\title{
Teatro, gênero e sociedade (1940-1968)
}

Heloisa Pontes

A apreensão das relaçōes entre o teatro, a cidade, a vida intelectual e a universidade, sob o prisma da história social da cultura e das relações de gênero, pressupõe uma atenção especial às marcas da experiência social e à sua retradução em formas simbólicas específicas. Entrelaçamento complexo, que exige para seu deciframento a mobilização de uma perspectiva analítica a um só tempo sincrônica e diacrônica. Sem o que não é possível entender e dar conta dos momentos em que tais relações se conformam em sentido convergente. Tampouco aqueles em que elas se expressam sob formas divergentes. Os trabalhos de Schorske e de Auerbach são dois exemplos eloquentes do quanto pode render a pesquisa sobre tais relações na pena de um historiador experiente e de um filólogo atilado às injunçôes entre forma e conteúdo social.

Atento às imbricações observadas no plano da dramaturgia e da composição social do público que gostava de teatro no século XVII e o frequentava, Auerbach mostra como a corte e a cidade compunham uma unidade. "La cour et la ville" - expressões que servem de título ao ensaio em tela são responsáveis pela criação do que podemos chamar de público, no sentido moderno. Entrelaçadas, elas fornecem, por meio de um conteúdo social transfigurado em forma teatral, a base para a sedimentação da tragédia francesa. Nas palavras de Auerbach, 
As duas partes dessa unidade [la cour e la ville] eram certamente distintas no plano formal, mas a linha divisória entre elas foi muitas vezes transgredida e, acima de tudo, cada uma das partes perdera suas bases autênticas. A nobreza perdera sua função e se reduzira apenas a um círculo em torno do rei; a burguesia, ou pelo menos a parte dela que pode ser designada como la ville, também se encontrava alienada de sua função original como classe produtiva. A ausência parasitária de qualquer função e o ideal cultural comum levavam la cour e la ville a fundir-se numa camada homogênea (Auerbach, 2007, p. 268).

Elegendo Viena como palco da cultura moderna, a-histórica, ligada à expressão dos sentimentos, aos domínios obscuros do erotismo e do inconsciente, e em revolta aberta contra o legado racionalista, Schorske mostra que as proposições estéticas, as convenções formais e o conteúdo substantivo das artes gestadas na cidade são inseparáveis da experiência social da elite que as produziu (cf. Schorske, 1993). Não é o caso aqui de rastrear o andamento analítico do historiador, e sim de sublinhar a maneira como ele desvela a relação entre "a graça e a palavra", ao abordar a universidade e o teatro como expressão da cultura liberal contra a qual irão opor-se os modernistas no final do século XIX. Enquanto a universidade se afirma como o lugar por excelência da cultura liberal, assentada na lei e na racionalidade burguesa, o teatro não perde os vínculos com a cultura plástica e sensual herdada da contrarreforma e da aristocracia. Centro da "educação sentimental" burguesa, o teatro, em Viena, mesmo quando remodelado na esteira das reformas urbanas promovidas pelos liberais, vincula-se, como dramaturgia e espaço de exibição mundana, à tradição aristocrática da "graça" (cf. Schorske, 1998).

Se em alguns contextos a relação entre o teatro, a universidade e a cidade sinaliza caminhos divergentes, em outros ela aponta para trilhas convergentes, que expressam similitudes formais e sociais. Tal foi o caso de São Paulo

1.Para um aprofundamento dessa questão, ver Pontes (2008). nas décadas de 1940 e $1950^{1}$. Na capital paulista, e nesse período, assiste-se à implantação de um sistema cultural denso e diversificado, que se expressará ao mesmo tempo no teatro e na vida intelectual, em função de mudanças produzidas na ordem da conjuntura - nada menos que uma guerra de proporções mundiais - e de alterações significativas na estrutura social da cidade. Na configuração desse sistema pesaram o perfil social de recrutamento dos envolvidos com a atividade teatral e intelectual, a montagem de instituições afinadas com os ideários artísticos e científicos de ponta na época, a presença de estrangeiros, professores e diretores, na formação da primeira 
geração de universitários treinados nas novas modalidades de trabalho intelectual, e também dos intérpretes profissionais e dramaturgos envolvidos com as concepções e as rotinas de trabalho do teatro moderno.

No teatro, encontravam-se diretores de nacionalidades diversas, como o judeu polonês Ziembinski, os franceses Jouvet e Henriette Morineau, os italianos Adolfo Celi, Ruggero Jacobbi, Gianni Ratto, Luciano Salce, Flamínio Bollini Cerri e Alberto D’Aversa, o belga Maurice Vaneau. Na universidade, os integrantes da Missão Francesa, como Jean Magüé, Claude Lévi-Strauss, Pierre Monbeig, Roger Bastide, entre outros.

Sob a pressão de escolhas políticas radicalizadas pela situação da Segunda Guerra Mundial na Europa ou sob os efeitos do pós-guerra, que encurtaram as possibilidades de realização profissional, vários deles permaneceram mais tempo no Brasil do que o previsto de início. Desse encontro entre um novo contingente de alunos e de atores amadores (oriundos em sua maioria de famílias intelectualizadas de classe média, várias delas de distintas procedências étnicas), numa cidade como São Paulo (que rapidamente ganhava ares e estatura de metrópole), com estrangeiros em início de carreira (como os professores da Missão Francesa) ou mais experientes (como os diretores de teatro citados acima) que para cá vieram em virtude da guerra, deu-se a implantação de um sistema cultural e intelectual complexo, sem precedentes na história brasileira ${ }^{2}$.

Daí a relevância de justapor duas experiências distintas, o teatro e o trabalho intelectual, para ressaltar a urdidura sociológica que os alinhavou sincronicamente em uma mesma trama cultural. Se as marcas que os intelectuais e os diretores estrangeiros deixaram na universidade e no teatro são indeléveis, diversas, no entanto, foram as maneiras como elas se fizeram presentes ou se impregnaram nas trajetórias e nas carreiras daqueles e daquelas que estiveram sob a sua influência ${ }^{3}$. Por isso, o interesse em desvelar a experiência dos herdeiros desse legado, adquirida em conjunto com a criação de uma nova sociabilidade intelectual e artística, novas linguagens, novas oportunidades de carreiras e novas maneiras de fazer um "nome", pelo prisma de sua refração na vida intelectual e na cena teatral paulista, tendo como pinça analítica as relações sociais de gênero.

O desafio deste artigo é, nesse sentido, duplo: 1) entender as razões que levaram o teatro a desfrutar de tamanha centralidade na cena cultural da metrópole paulista; 2) explicar o prestígio conquistado pelas atrizes Fernanda Montenegro (1929), Cacilda Becker (1921-1969), Cleyde Yáconis (1923), Maria Della Costa (1926), Tônia Carrero (1922) e Nydia Lícia (1925) no
2. Para uma análise densa e sofisticada do entrelaçamento entre o processo de metropolização da cidade de São Paulo e a produção de novas linguagens culturais, ver Arruda (2001).

3. Para perscrutar a reverberação da presença dos estrangeiros na cena cultural paulista usei como contraponto o Rio de Janeiro e Nova York. Um detalhamento maior dessa comparação encontrase em Pontes (2004, pp. 183-204). 
4. Trecho da entrevista que Maria Della Costa concedeu ao jornal A Tribuna de Santos, em 26/2/1984.

5. Como o Grupo Universitário de Teatro, dirigido por Décio de $\mathrm{Al}$ meida Prado, o Grupo de Teatro Experimental, dirigido por Alfredo Mesquita, o Teatro do Estudante, criado e dirigido inicialmente pelo diplomata Paschoal Carlos Magno, e Os Comediantes, responsáveis pela encenação de Vestido de noi$v a$, de Nelson Rodrigues, tida por todos e desde a sua estreia no Rio de Janeiro, em 1943, como o marco zero do moderno teatro brasileiro. Para uma visão geral do teatro brasileiro no período, ver Prado (1988). decorrer dos anos de 1940 e 1950. Quando então, nas palavras de Maria Della Costa, "as mulheres mandavam no teatro" ${ }^{4}$. Essa experiência, longe de ser autoevidente, contrasta com a vivência das atrizes que as sucederam em termos geracionais, caso, por exemplo, de Dina Sfat (1938-1989), que se projetou na cena teatral paulista em 1963, após a inserção no Teatro de Arena. Reconhecida como atriz de teatro, televisão e cinema, Dina Sfat lamentava-se por ter feito menos cinema do que gostaria. Em suas palavras:

Eu poderia ter feito grandes filmes e grandes personagens. Mas esses grandes filmes e grandes personagens não aconteceram na minha geração. Os filmes eram feitos, quase sempre, para personagens masculinos. O Cinema Novo era todo voltado para o homem, as mulheres funcionavam como enfeite de bolo. [...] Os exemplos são vários e incluem os filmes de Glauber Rocha. Ele mesmo dizia com a maior graça, mas com total franqueza - que o mundo tem o lado masculino e o lado negativo. As mulheres fizeram cinema e teatro, sim: Maria Della Costa, Fernanda Montenegro, Cacilda Becker, Natália Thimberg, Tônia Carrero, todas ativíssimas. Mas no teatro do meu tempo, dos meus 20 anos [referência ao teatro dos anos de 1960], que seria o Teatro de Arena, era assim: Gianfrancesco Guarnieri e nós, mulheres, o complemento, a massa (Sfat e Caballero, 1988, pp. 232-233).

A leitura em conjunto dos depoimentos de Maria Della Costa e de Dina Sfat ajuda a situar a questão da autoridade artística. Mas não esgota o problema, uma vez que a importância (ou não) das mulheres no teatro e o renome conquistado só podem ser explicados à luz das convenções teatrais e de gênero. Por ser um dos bens mais prezados e cobiçados nos campos de produção simbólica, o "nome próprio", como mostram Bourdieu e Yvette Delsaut (1975), funciona como uma marca ou uma "grife" que, em virtude de processos intrigantes de alquimia social, tem o efeito "mágico" de produzir uma "curiosa contaminação de prestígio" para tudo e todos que gravitam ao seu redor.

No caso do teatro brasileiro, o prestígio decorrente dessa "assinatura" é inseparável dos empreendimentos que viabilizaram a implantação de sua dimensão propriamente moderna. De um lado, os grupos amadores criados na década de 1940 e integrados por jovens de classe média ou de elite 5 . De outro, os projetos que implicaram a profissionalização da atividade teatral, como o Teatro Brasileiro de Comédia (TBC), símbolo do teatro paulista na virada da década de 1940 e referência obrigatória nos anos de 1950, assim 
como várias companhias que surgiram no período. Nelas as atrizes tiveram uma projeção excepcional. O prestígio alcançado deve-se tanto à transferência da autoridade social e cultural do público de extração burguesa que frequentava o teatro, como à participação das intérpretes no movimento de implantação e sedimentação dos princípios estéticos e das rotinas de trabalho do teatro moderno.

Alinhado à produção cultural erudita, esse tipo de teatro não perdeu a ligação com a tradição do teatro popular ou de feitio mais tradicional, apesar da origem social diversa de seus integrantes, recrutados predominantemente "junto a camadas sociais diferentes daquelas que desde o século XIX geravam os elencos nacionais, em geral de origem bastante humilde" (Brandão, 2002, p. 72). Sem perder de vista as diferenças consideráveis entre um e outro - expressas no trabalho dos diretores e dos cenógrafos, na escolha do repertório, nas exigências do ensaio prolongado, na eliminação do ponto e dos $\operatorname{cacos}^{6}-$, a presença da primeira atriz continuou a ser central na montagem e no sucesso dos empreendimentos teatrais modernos. Prova disso são as companhias que se formaram a partir dos conflitos profissionais ou amorosos ocorridos entre os integrantes do elenco do Teatro Brasileiro de Comédia (TBC), como as de Madalena Nicol e Ruggero Jacobbi; Nydia Lícia e Sérgio Cardoso; Tônia Carrero, Adolfo Celi e Paulo Autran; Cacilda Becker e Walmor Chagas. Ou, ainda, a companhia de Maria Della Costa e Sandro Polônio.

Nesse cenário, a cidade de São Paulo protagonizou um papel central. Mais provinciana e paradoxalmente mais cosmopolita que o Rio de Janeiroentão capital política e, em vários aspectos, cultural do país -, ela se tornou, a partir de meados dos anos de 1940, o centro das experimentações no âmbito da cultura. Concomitante às alterações que se produziam em passo acelerado na cidade, o teatro se antecipou "aos estudos sociais, encarregando-se da tarefa realizada no Nordeste pelo romance” (Mello e Souza, 1980, p. 110). A retradução dessa experiência social no plano formal da linguagem deu-se em São Paulo pela via da dramaturgia (e também das ciências sociais). Nas palavras de Gilda de Mello e Souza,

A decadência de todo um setor da sociedade [a oligarquia agrária] era compensada pelo desenvolvimento de outro e a perda de prestígio do fazendeiro se cruzava com a ascensão econômica e social do imigrante. Presenciava-se, sem fôlego, uma substituição simétrica de estilos de vida e não o lento desaparecimento de um mundo cuja agonia se pudesse acompanhar com lucidez (Idem).
6. Eliminado no teatro moderno, o ponto era uma presença obrigatória no teatro popular, no qual os atores e as atrizes, submetidos a outro ritmo e concepção de trabalho, não tinham tempo nem se preocupavam em decorar as falas. Contavam, para tanto, com o ponto, que, escondido da plateia, se encarregava de repassar o texto. Outras características desse teatro eram os "cacos", as falas e deixas improvisadas na hora do espetáculo que nada tinham a ver com o texto original encenado. A atriz Dercy Gonçalves, comediante de mãocheia, notabilizou-se junto ao público por esse tipo de desempenho. 
Graças ao encontro de um dramaturgo em início de carreira, o paulista Jorge Andrade (1922-1984), de uma jovem atriz em ascensão, Fernanda Montenegro, e de um diretor experiente, o italiano Gianni Ratto (19162005), o público paulista que frequentava o teatro pôde ver no palco a experiência objetivada da decadência social de setores expressivos das elites dirigentes, integrados pela oligarquia agrária.

A mais carioca das atrizes que passaram pelo TBC, portadora de uma das poderosas assinaturas da história do teatro brasileiro, Fernanda Montenegro tinha 25 anos quando encenou $A$ moratória, um ano depois de se transferir do Rio de Janeiro para São Paulo. Da antiga capital federal, ela trouxe uma experiência teatral rica e diversificada, mesclada pela influência do circo e do teatro popular e pela participação nos primórdios da televisão. Em São Paulo, ela recebeu a contribuição "imensa dos diretores vindos de outra esfera cultural", que levaram para o Brasil "a visão vertical do espetáculo" (Montenegro, 1998, p. 23). Dentre todos os diretores estrangeiros com quem trabalhou, Gianni Ratto foi de longe a influência mais marcante. Com ele aprendeu a desentranhar a interioridade das personagens que representava nos palcos e descobriu que havia uma "história dentro da arte teatral" (Idem, ibidem). Com ele, projetou-se na cena paulista e ganhou prestígio nacional.

Assim como sucedera com o polonês Ziembinski (1908-1978), que em 1943, dois anos depois de fixar residência no país, dirigiu a peça Vestido de noiva, de Nelson Rodrigues, considerada uma espécie de marco zero do teatro brasileiro, Gianni Ratto foi sensível ao que de mais importante estava despontando na dramaturgia paulista. $\mathrm{O}$ temor que ele tinha de dirigir um texto que fosse "excessivamente preso a motivos e razões exclusivamente regionais e nacionalistas" era proporcional à necessidade que sentia de encenar autores brasileiros. Cenógrafo inventivo e experiente, para quem a "beleza formal" do espetáculo deveria integrar-se a uma "interpretação em profundidade das personagens e do texto" (Ratto, 1996, p. 80), Gianni Ratto formou-se no espírito do Piccolo Teatro de Milão (criado em 1947). Ali trabalhou ao lado de Giorgio Strehler e Paolo Grassi, partilhando com eles a ideia de que o aprimoramento da cena teatral exigia mais que a escolha certa de um texto clássico da dramaturgia ocidental e a solução de problemas técnicos de direção e formação de atores. Pressupunha, antes de tudo, um lastreamento na dramaturgia nacional. Por isso, em 1955, em menos de um ano de residência no Brasil, Gianni Ratto encontrou na peça A moratória, de Jorge Andrade, o dramaturgo brasileiro que precisava para 
pôr à prova suas concepções como diretor e cenógrafo. Em suas palavras, emitidas em 1955,

Lendo $A$ moratória percebi logo que as palavras de [suas personagens] eram as palavras da minha gente e podiam pertencer a qualquer pessoa de qualquer nacionalidade. $\mathrm{O}$ tema também era comum a nós e o assunto - ligado a um acontecimento da história econômica do Brasil - era coincidente à nossa história de homem de hoje, vivendo uma crise de ordem moral da qual com muito esforço somente agora - há dez anos da guerra - conseguimos sair ${ }^{7}$.

Do encontro entre o diretor experiente, o dramaturgo que melhor retratou as alterações que se produziam na paisagem social paulista e a atriz em ascensão, produziu-se um marco no teatro da metrópole. O impacto em São Paulo de $A$ moratória, similar ao de Vestido de noiva no Rio de Janeiro em 1943, foi acompanhado de perto pela nova geração de intelectuais formada pelos professores estrangeiros que se vincularam à Faculdade de Filosofia, Ciências e Letras da Universidade de São Paulo, e em sintonia com os experimentos de ponta no teatro paulista. Entre eles, a Escola de Arte Dramática, criada por Alfredo Mesquita, em 1948, no mesmo ano do Teatro Brasileiro de Comédia. Nessa escola, Jorge Andrade, seguindo um conselho da atriz Cacilda Becker, também professora por lá durante um tempo, iniciou-se nas manhas da dramaturgia e aprimorou-se na linguagem teatral. Premiado em 1954, como autor revelação, pelo texto O telescópio, foi com $A$ moratória que seu nome se firmou no rol da melhor dramaturgia brasileira e se associou à linguagem moderna que estava sendo gestada em São Paulo no teatro, nas artes plásticas e nas ciências sociais (cf. Arruda, 2001).

Revelando um "autor prisioneiro, como as suas personagens, do espaço e do tempo perdido da fazenda" (Mello e Souza, 1980, p. 115), A moratória encena as consequências da crise internacional de 1929 e seu rebatimento na economia paulista pelo prisma de uma família arruinada. Seus membros, antes de serem caracterizados com os traços da psicologia individual, são, como mostra Gilda de Mello e Souza, "o Pai, a Mãe, o Filho, a Filha; e os atos, pensamentos e desejos que deles derivam ligam-se menos à história isolada de cada um do que à história da propriedade a que pertencem. É a perda da fazenda que explica a revolta do pai, o fracasso do filho, a crispação subterrânea da filha, a desencantada abnegação da mãe" (Idem, p. 114).

A peça mostra a habilidade do dramaturgo para justapor cenicamente o passado e o presente. Nas palavras do crítico e historiador do teatro, Sábato
7. Esse depoimento de Gianni Ratto encontra-se no programa da peça Amoratória, encenada em maio de 1955. 
Magaldi, na época também professor de Jorge Andrade, a maestria dele residia na maneira como jogava com os "planos do presente (1932) e do passado (1923)", de tal forma que o segundo não se convertia em "mero flashback ilustrador do drama final. A maestria técnica era tão admirável que, na dinâmica do texto, frequentemente um episódio de 1932 parecia preparar o que ocorreu em 1929" (Magaldi, 1986a, p. 673). Para alcançá-la, Jorge Andrade releu Vestido de noiva, de Nelson Rodrigues, e revirou pelo avesso os andaimes de sua construção, seguindo um conselho de Magaldi de que ali encontraria a inspiração necessária para resolver em sua peça o problema da passagem do tempo. A solução encontrada em $A$ moratória somava-se à habilidade do cenógrafo e diretor da montagem, Gianni Ratto, que dividiu o cenário em duas partes expostas em diagonal. Uma delas correspondia à opulenta fazenda de café do passado de 1929; a outra, à modesta casa na cidade do presente, situado em 1932, sugerindo, assim, "a paralisação do tempo numa realidade superior e esmagadora” (Idem, ibidem).

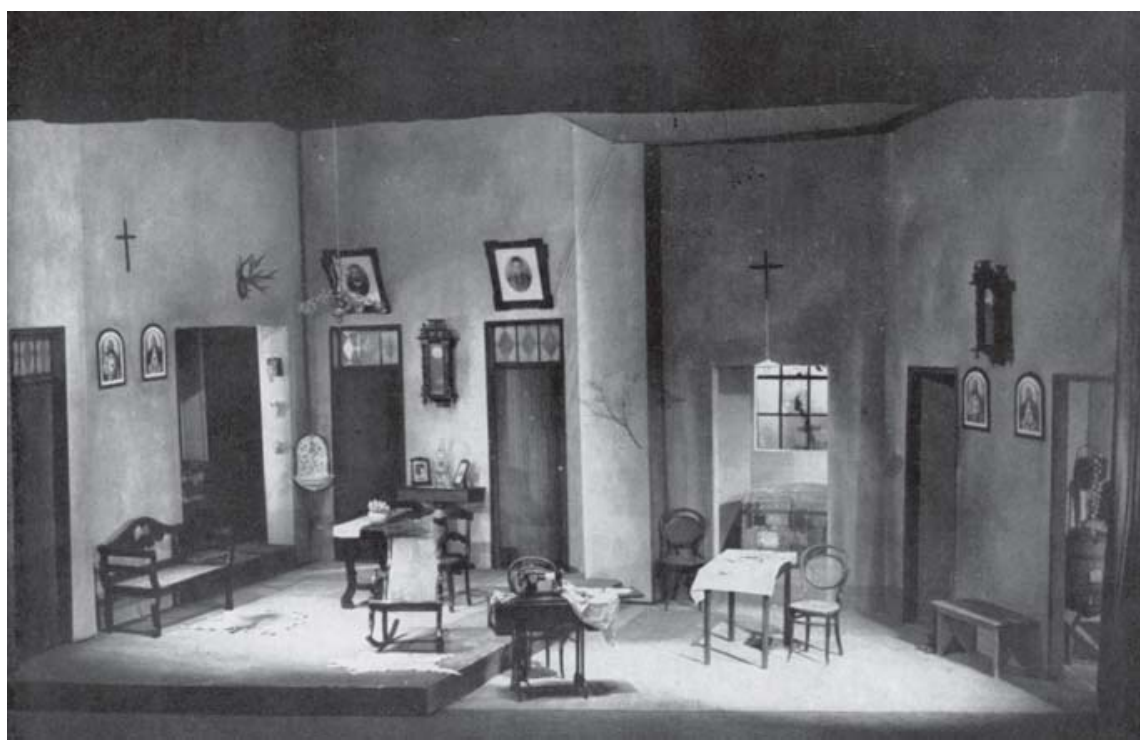

A foto do cenário aqui reproduzida evidencia visualmente o rebaixamento social da família: o banco rústico no lugar do assento de palhinha, o filtro no lugar do lavabo de porcelana inglesa, a máquina de costura no centro da sala. No cenário urbano da ruína familiar foram preservados o crucifixo e os quadros dos santos. $\mathrm{O}$ único objeto que sobrou do passado glorioso na fazenda foi o relógio de parede. Não aleatoriamente, ele ganha nesse ambiente "rebaixado" a centralidade que os retratos dos antepassados têm no cenário 
da opulência. O domínio técnico do cenário apoiava-se no conhecimento por inteiro da realidade social que o dramaturgo estampara no texto e que o diretor ajudaria os intérpretes a corporificar no palco. Quem captou, com requintes de análise, essa transmutação da experiência social de Jorge Andrade em linguagem teatral foi o crítico e historiador maior do teatro brasileiro, Décio de Almeida Prado (1917-2000). Ligados por laços de parentesco que quase prescindem da consanguinidade biológica e se convertem numa "espécie de ficção social, mantida respeitosamente em meios estáveis e conservadores como os rurais", ambos foram criados "dentro de idêntica paisagem social" (Prado, 1986, p. 625), representada pela vida das elites agrárias nas fazendas: espaço do mando, da moradia e da sociabilidade. Décio, de longe e de passagem, nas férias escolares, quando voltava à fazenda da família materna. Jorge Andrade, de perto e de dentro, "entranhadamente imerso nessa realidade humana que viria, mais tarde, a constituir o seu território literário de eleição como autor de teatro" (Idem, p. 626). Nas palavras do primo longínquo:

A moratória evoca o fim, frequentemente melancólico, desse processo social: a divisão e perda das fazendas, com a ascensão de novas classes, facilitada por dois violentos choques: a crise do café e a revolução de trinta (ambas, não é preciso acrescentar, extremamente benéficas à democratização do país). Não compreenderá nada do alcance da peça quem não pressentir, por detrás dos indivíduos e dos episódios particulares que ela narra, a agonia de uma sociedade em vias de transição, aquela dolorosa passagem do Brasil dos fazendeiros para o Brasil urbano tão bem descrita por Gilberto Freyre (Idem, ibidem).

Justapondo os planos do passado e do presente e, ao mesmo tempo, a ambiência social retratada nos dois cenários, a peça expõe o dilaceramento da família, evitando a armadilha fácil da história contada em sequência cronológica. O espectador, sabendo mais que as personagens sobre o destino social que as espera, compreende, antes delas, as marcas e os sofrimentos impressos pela transição e declínio do universo em que se movimentam. "Qualidades e defeitos de toda uma classe são retratados com igual comoção e igual lucidez", segundo Décio de Almeida Prado (Idem, p. 627). A observação do crítico, aludindo ao esforço de objetivação do dramaturgo em relação ao mundo social que foi o dele e é o de suas personagens, ganha registro sociológico na análise de Maria Arminda do Nascimento Arruda. Em suas palavras: 
O tempo objetivo de declínio da sociedade agrária coabita o movimento de subjetividade das personagens, lançadas em contextos que solapam e negam o que parecia inscrito nos seus destinos sociais. Posta ao lado das figuras identificadas com a sociedade urbano-industrial, a dramaturgia [de Jorge Andrade] reproduz essa história em dilaceramento, de onde retirou a matéria viva de seu teatro, testemunho pungente de um mundo fenecente e de outro em ascensão (Arruda, 2001, p. 137).

O vigor de $A$ moratória foi reforçado pela interpretação do elenco escalado em 1955, para a sua primeira montagem nos palcos de São Paulo. Dentre os atores, Fernanda Montenegro, que infundiu verossimilhança e verdade cênica em voltagem máxima à protagonista da peça. No papel de Lucília, a "única personagem da família de fazendeiros que abandona a lamúria pela fortuna perdida e enfrenta com decisão a realidade" (Magaldi, 1986b, p. 650), ela ganhou a plateia e a crítica. Realista e avessa ao exercício complacente do autoengano, empenhada na sobrevivência da família com o auxílio da máquina de costura que lhe serviu de hobby quando menina rica e bemvestida, e que, no momento de seu descenso, tornou-se a fonte de sustento da família, Lucília expõe sem meios tons e sem meias verdades a ruína social que dilacera a todos. Aquilo que Décio de Almeida Prado enxergou como próprio das mulheres dessa classe, o realismo nutrido pela dedicação ao trabalho doméstico, Gilda de Mello e Souza tentou explicar em chave mais abstrata e sociológica, tal como desenhada pela literatura especializada que ela lia na época, quando escreveu em 1956 o ensaio "Teatro ao sul”, voltado para a análise da dramaturgia paulista:

$\mathrm{Na}$ ordem que se esboroa, Lucília é o último esteio. A literatura sociológica já nos alertara para esse fenômeno da acomodação feminina nos momentos de crise. Ser secundário, de existência subalterna, não lhe é tão penoso trocar uma sujeição por outra, o domínio do pai ou do marido pela escravidão da máquina de costura. Pois assim como a fazenda desenvolveu em Quim [o pai de Lucília] o instinto de mando e em Marcelo [o irmão] o ódio a qualquer sujeição, treinou Lucília nas tarefas miúdas de dentro de casa, nos pequenos gestos, na economia cotidiana. A sua força é da criatura sem liberdade, empenhada nos compromissos, na aceitação do mundo e do presente. Por isso, apenas ela conseguirá se libertar da fazenda e penetrar no novo universo que se constrói (1980, p. 115).

Lucília, a filha de uma família de elite arruinada, ao ser corporificada pela atriz, filha de uma família operária, entrou para o rol das personagens 
femininas marcantes do teatro brasileiro. E alçou Fernanda Montenegro a uma posição destacada na hierarquia das grandes intérpretes da época, cuja figura dominante era Cacilda Becker, atriz que melhor expressou o polo modernizador do teatro brasileiro, por sua adesão de corpo e alma à cena teatral paulista, que, por mais de uma década, ofuscou o teatro carioca ${ }^{8}$. Este só se modernizaria em meados dos anos de 1950, quando vários intérpretes que passaram pelo Teatro Brasileiro de Comédia voltaram a residir no Rio de Janeiro, como Tônia Carrero e Fernanda Montenegro, para citar duas das mais renomadas atrizes da época.

O prestígio conquistado por elas é inseparável do reconhecimento que tiveram como intérpretes. Mas não só. Ele é também uma derivação da autoridade cultural e social desfrutada pelo público burguês que frequentava o teatro paulista na época, em especial o TBC. A criação dessa companhia, em conjunto com a formação de grupos amadores, alterou o status das atrizes, vistas no Brasil (mas não só) como mulheres de "vida fácil" e moral "duvidosa”, próximas socialmente das prostitutas, por sua identificação com o teatro de extração popular e com as casas noturnas de reputação controversa.

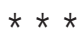

A notoriedade das atrizes que passaram pelo Teatro Brasileiro de Comédia, antes de fundarem suas próprias companhias, é um tema fascinante para uma etnografia das relaçôes de gênero interessada na relação entre nome e corpo, e suas articulaçôes com o problema da autoria e da autoridade cultural, entre 1940 e final dos anos de 1960. Ela permite iluminar os contrastes entre os campos intelectual e teatral'. A apreensão, em chave comparativa, das diferenças e das similitudes nesses dois domínios, no momento em que eles tinham ligações mais estreitas do que as que se observam hoje, permite captar os constrangimentos, os espaços possíveis e as perspectivas distintas de carreira que se abriram para as intelectuais e para as atrizes.

Intérpretes da metrópole, foram tanto as intelectuais como as atrizes que entraram em cena no período. Assim como foram os parceiros que elas tiveram ao longo de suas trajetórias. Mas, enquanto algumas das intelectuais que mais se destacaram na época, como as críticas de cultura Patrícia Galvão (1910-1962), Lúcia Miguel Pereira (1901-1959) e Gilda de Mello e Souza (1919-2005), eram mulheres excepcionais, no sentido de que, ao se inserirem num campo marcadamente masculino, sofreram, com maior ou menor intensidade, os reveses dessa condição, e fizeram valer o capital cul-
8. Para uma análise densa das razōes que fizeram com que o TBC e a cidade de São Paulo assumissem essa posição proeminente, ver Brandão (1988, pp. 110120); Arruda (2001); Mattos (2002).

9. Para uma discussão vigorosa sobre a relação entre nome, renome e gênero, assim como sobre a questão da "notoriedade retrospectiva”, isto é, o modo "como o renome adquirido a partir de um certo momento pode iluminar a vida inteira de um personagem" e ofuscar a de outro, verCorrêa (2003, p. 22) e também Euletério (2005). 
10.Para um desenvolvimento desse ponto, ver Pontes (no prelo).

11.Para a contextualização dessa discussão no panorama dos dilemas enfrentados pela intelectualidade brasileira, ver Oliven (2001). tural conquistado por meio de uma escolarização elevada ou de relações sociais entranhadas na atividade cultural ${ }^{10}$, as atrizes fizeram nome e firmaram a autoridade artística num domínio menos culto e escolarizado, e bem mais aberto à presença feminina. Não havia, no período em que entraram em cena, escolas ou faculdades de teatro e artes cênicas. Quando a primeira delas foi criada, a Escola de Arte Dramática, por iniciativa de Alfredo Mesquita, no mesmo ano da inauguração do Teatro Brasileiro de Comédia (1948), algumas dessas atrizes, como Cacilda Becker, passaram por lá como professoras, e não como alunas. Discípulas mesmo elas foram dos diretores estrangeiros, estes sim detentores de uma elevada cultura teatral. A formação que deles receberam foi filtrada e redesenhada nas companhias que montaram com a colaboração ativa de seus parceiros.

A maior ou menor ousadia na política de repertório, na escolha das personagens que protagonizaram, no afinamento do elenco com o debate cultural e com a progressiva radicalização política da época deve muito ao perfil doutrinário e às escolhas estéticas dos diretores estrangeiros com quem trabalharam. Exemplo disso encontra-se na reverberação das parcerias de Tônia Carrero e Adolfo Celi, e de Fernanda Montenegro e Gianni Ratto, no perfil das companhias em que ambas figuraram como atrizes principais. A primeira situada no polo mais conservador e burguês do teatro moderno; a segunda, localizada no plano mais experimental da cultura teatral. Nesse espectro, a Companhia de Maria Della Costa representa a contribuição mais ousada em termos políticos e culturais, como bem demonstram as encenações de Anjo negro, de Nelson Rodrigues, A moratória, de Jorge Andrade, Gimba, de Guarnieri, e a primeira montagem de Brecht no Brasil, $A$ alma boa de Se-Tsuan, em 1958. No centro desse diapasão de política cultural, encontravam-se as companhias de Nydia Lícia e Sérgio Cardoso e de Cacilda Becker e Walmor Chagas. Num misto de deliberação própria e pressão dos setores e do público mais à esquerda do campo teatral, que capitaneou o debate sobre o nacional-popular ${ }^{11}$, elas mesclaram uma aposta no autor brasileiro com uma predominância do teatro comercial de sucesso.

$\mathrm{Na}$ conjuntura de transformação por que passava a cultura brasileira, sinalizada pelo cinema novo em gestação e pelo intrincado entrelaçamento entre o teatro, o rádio e o início da televisão, a profissionalização da cena teatral moderna foi possível graças à contribuição decisiva dos diretores estrangeiros e das companhias formadas pelas atrizes mencionadas neste artigo, todas elas saídas ou com passagem pelo TBC. Nesse processo complexo de afirmação pesou também o recado político e social dos grandes 
dramaturgos brasileiros do período. Nelson Rodrigues, Jorge Andrade e Gianfrancesco Guarnieri, entre os principais, ajudaram a converter o teatro em suporte de uma renovação radical na maneira de apreender a experiência contemporânea da sociedade brasileira. Suas peças dramatizavam conflitos sociais lancinantes - o declínio das elites rurais, as vicissitudes dos setores médios, o impacto da vida urbana nos costumes e nas relaçôes familiares, a ascensão da classe operária -, fazendo do palco, dos diretores, das atrizes e seus parceiros os protagonistas de uma cultura figurativa que foi o retrato do país nesse momento crucial de crise de uma velha ordem e arranque para nova etapa de expansão econômica e social.

Nessa figuração em novos ângulos da sociedade brasileira, houve lugar para que a origem social precária ou remediada de várias atrizes (Cacilda Becker, Cleyde Yáconis, Maria Della Costa, entre outras) se convertesse em suporte expressivo da atividade teatral. Que essa atividade, ao contrário do que ocorre em outros campos de produção simbólica, tenha se valido disso, que, em princípio, pode ser tido e vivido como uma deficiência, é revelador de certos traços decisivos para se entender a dinâmica da sociedade brasileira na época. Muitas atrizes eram praticamente destituídas de escolaridade e de capital cultural, enquanto outras, oriundas do teatro amador (como Nydia Lícia), se valeram desse tipo de trunfo para se firmar na cena teatral. A maioria provinha de famílias de imigrantes e pertencia à geração que conseguiu estabilizar a trajetória familiar com o trabalho delas no palco. Provenientes das mais diversas latitudes dos escalóes inferiores e remediados da estrutura social brasileira, essas atrizes infundiram os modos, as dicções, a corporalidade, a expressividade, as graças, os sinais de uma energia social que cintilava e reverberava no palco a mobilidade geográfica e societária característica desse momento de transformações por que passavam as metrópoles no país.

Esse momento crucial de formação e sedimentação do que estou chamando por sistema cultural moderno, diversificado e adensado, que se manifestou, ao mesmo tempo e por razóes similares, no teatro e no campo intelectual, inicia-se nos anos de 1940 e estende-se até 1968. Na década de 1940 assiste-se à montagem das condições sociais, artísticas e institucionais que presidiram a implantação e sedimentação do teatro moderno brasileiro, que, sob vários aspectos, representou uma ruptura com o teatro popular, especialmente com o teatro de revista ${ }^{12}$. A criação de grupos amadores e a fundação do Teatro Brasileiro de Comédia introduziram novas maneiras de conceber o repertório e o trabalho de atores, atrizes, diretores e cenógrafos.
12.Produção tipicamente nacional, "com sua graça irreverente, às vezes de mau gosto, seu tom de caçoada, sua crítica aos costumes e suas alegorias a respeito da vida e da política nacionais, o teatro de revista foi, sem dúvida, até meados do século $\mathrm{XX}$, o gênero mais característico do teatro brasileiro, aquele que mais empolgou o público" (Mattos, 2002, p. 108). 
13. Para uma visão geral desses novos empreendimentos culturais e teatrais, ver $\mathrm{Ri}$ denti (2000).
Sedimentado ao longo dos anos de 1950, esse panorama sofreu modificações importantes no decênio de 1960 com a atuação de novos grupos teatrais, como o Teatro de Arena, o Oficina e os Centros Populares de Cultu$\mathrm{ra}^{13}$. Eles foram responsáveis pela valorização do autor nacional, pela introdução de novas convenções teatrais e por uma nova articulação entre cultura e política no domínio da dramaturgia. No período que se estende até 1968 havia uma "relativa hegemonia cultural da esquerda" (Schwarz, 1978, p. 62), apesar do golpe militar e da ditadura, e o país, nas palavras de Roberto Schwarz, "estava irreconhecivelmente inteligente" (Idem, p. 69).

Como resultado da entrada em cena de novos grupos e de um novo público, jovem, universitário e de esquerda, houve uma "alteração social do palco" (Idem, p. 81), e o teatro de repertório, que por quase duas décadas fora o espaço de projeção das atrizes aqui mencionadas, perdeu a centralidade que tivera até então. "Mudanças estruturais no campo artístico" - correlatas à alteração do perfil social e cultural do novo público e à sedimentação do "conceito de engajamento artístico de esquerda" (Napolitano, 2001) fizeram com que "o bom teatro, que durante anos discutira em português de escola o adultério, a liberdade, a angústia, [parecesse] recuado de uma era" (Schwarz, 1978, p. 81) - para completar o raciocínio com a formulação precisa de Schwarz. Essa combinação entre "a cena 'rebaixada' e um público ativista" (Idem, ibidem) produziu uma vitalidade extraordinária no palco, uma resposta vibrante do público engajado e o fim do ciclo do teatro moderno que se instalara no país no decênio de 1940. A montagem da peça Roda-viva, de Chico Buarque de Holanda, levada à cena em 1968, por José Celso Martinez Corrêa, marcou o fim desse ciclo, inaugurado simbolicamente em 1943, com Vestido de noiva, de Nelson Rodrigues. A partir de Roda-viva quebrou-se a estrutura formal do palco "italiano" e a ilusão produzida pela "quarta parede", central para a convenção de que aquilo que os atores fazem no palco não é visto pela plateia. O happening e a antropofagia de Oswald de Andrade foram incorporados, e o teatro transformou-se em “ritual alegórico" (Prado, 2002, p. 519). Paralelamente à ascensão da televisão e das telenovelas, assiste-se a uma transformação da prática teatral. Como mostra João Roberto Faria, "o conceito de grupo substitui, nos anos de 1970, o de companhia, favorecendo outro tipo de produção, como a criação coletiva” (2006, p. 5).

Razões externas à história do teatro brasileiro também estão presentes na delimitação do recorte cronológico adotado neste artigo. $\mathrm{O}$ fato de o teatro ser uma das produçôes culturais mais diretamente entrelaçadas com 
as dinâmicas e os constrangimentos extra-artísticos faz dele um espaço de investigação privilegiado para deslindar as dimensōes de gênero e as convenções culturais e sociais que modelaram a carreira das atrizes. Mais "feminino" que o campo intelectual no período, ele ilumina, por contraste, os espaços possíveis, os recursos utilizados, os constrangimentos enfrentados pelas mulheres que fizeram nome como intelectuais e críticas de cultura. Isto não significa que as clivagens de gênero estivessem ausentes do teatro. $\mathrm{Na}$ divisão de trabalho que presidia a carpintaria teatral na época, elas estavam lá, mas com inflexões distintas. Enquanto o trabalho de ator era facultado a homens e mulheres, o da dramaturgia era privilégio ou atributo dos homens. Entre o polo mais "feminino" da representação, ocupado por atores e atrizes, e o mais "masculino" da dramaturgia, exercido pelos autores, encontravam-se os diretores e as ensaiadoras, com claro e diferenciado reconhecimento para os primeiros. Nos grupos e nos elencos, a figura da primeira atriz, remodelada pelas concepçōes do teatro moderno, continuou a ter grande centralidade, mesmo quando o nome dela não vinha estampado no nome da companhia. Tal foi o caso do Teatro dos Sete, que desde o início esteve associado, pelo público e pela crítica, à sua intérprete mais importante, Fernanda Montenegro.

Para a manutenção de tal centralidade, as mulheres fizeram valer a competência adquirida como atrizes, com a anuência e o apoio de seus parceiros. Não aleatoriamente singularizaram ou mesclaram seus nomes artísticos aos de suas companhias, quando saíram do TBC ou se firmaram ao lado dele, caso do Teatro Popular de Arte, que, após a transferência para São Paulo, passou a ser reconhecido como Teatro Maria Della Costa. As maneiras como as intérpretes viabilizaram o estrelato foram distintas. Ora compartilharam a condição de protagonistas com seus parceiros preferenciais, caso de Nydia Lícia com Sérgio Cardoso, de Tônia Carrero com Paulo Autran e mesmo de Cacilda Becker com Walmor Chagas, no embate feroz em Quem tem medo do Virginia Woolf? (encenada em 1965); ora amoldaram-se ao projeto coletivo dos grupos que lideravam, como Maria Della Costa e Fernanda Montenegro, nos quais elas podiam inclusive não figurar no elenco e, mesmo assim, se manterem à testa do empreendimento.

A situação das atrizes era bastante distinta daquela vivida pelas intelectuais e críticas de cultura. Não que os nomes delas - ou pseudônimo, como Mara Lobo, com o qual Patrícia Galvão estreou na ficção - não tenham sido estampados nos livros que escreveram. Tampouco que não pudessem galgar posiçōes mais sólidas, decorrentes da autoria e da autoridade intelectual a ela 
associada, caso de Lúcia Miguel Pereira. E, sim, que as instâncias de controle e de prestígio, ocupadas prioritariamente pelos homens, só seriam franqueadas às intelectuais acadêmicas, como mostra a trajetória de Gilda de Mello e Souza, bem mais tarde e de forma muito mais tortuosa do que a enfrentada pelos seus colegas da profissão. Tais consideraçôes não visam essencializar marcadores sociais de gênero e muito menos encapsular as trajetórias das mulheres reais sob o feixe anêmico de uma suposta condição comum de sujeição. O que se pretende é pôr em relação trajetórias, carreiras, parcerias, constrangimentos e recursos alocados em espaços sociais específicos, como são os campos de produção cultural, marcados eles mesmos por clivagens internas de gênero, que replicam com conteúdos específicos as clivagens decorrentes da maior ou menor proximidade que mantêm com o campo político. Quanto mais distante dele, mais a atividade cultural que empreendem é vista e associada ao polo feminino. Ao contrário, quanto mais próximo do campo político, maior a associação com o polo masculino e com os princípios e estilos socialmente definidos de masculinidade e feminilidade. Se estiver correto, tal procedimento explica as maneiras e as razões que levaram os campos intelectual e teatral a serem mais ou menos refratários à presença e à atuação das mulheres, no momento em que ambos se inscreviam numa mesma trama cultural, urdida pela metrópole em expansão e pela convergência entre a "palavra", o "gesto" e a "graça".

\section{Referências Bibliográficas}

Arruda, Maria Arminda do Nascimento. (2001), Metrópole e cultura: São Paulo meio de século. Bauru, Edusc.

Auerbach, Erich. (2007), “La cour e la ville”. In: Ensaios de literatura ocidental. São Paulo, Duas Cidades.

Bourdieu, Pierre \& Delsaut, Yvette. (1975), "Le couturier et sa griffe: contribuition à une théorie de la magie". Actes de la Recherche en Sciences Sociales.

Brandāo, Tânia. (1988), Peripécias modernas: Companhia Maria Della Costa. Rio de Janeiro, tese de doutorado em História, UFRJ, 2 vols.

- (2002), Teatro dos Sete: a máquina de repetir e a fábrica de estrelas. Rio de Janeiro, 7 Letras.

CorrêA, Mariza. (2003), Antropólogas e antropologia. Belo Horizonte, Editora da UFMG.

Euletério, Maria de Lourdes. (2005), Vidas de romance: as mulheres e o exercício de ler e escrever no entresséculos, 1890-1930. Rio de Janeiro, Topbooks. 
FARIA, João Roberto. (2006), "Entrevista concedida a Nelson de Sá". Folha de S. Paulo, Suplemento Mais, 30 abr.

Magaldi, Sábato. (1986a), "Um painel histórico: o teatro de Jorge Andrade”. In: Andrade, Jorge. Marta, a árvore, o relógio. 2. ed. São Paulo, Perspectiva. . (1986b), "Dos bens ao sangue". In: ANDRADE, Jorge. Marta, a árvore, o relógio. 2. ed. São Paulo, Perspectiva.

MatTos, Davi José Lessa. (2002), O espetáculo da cultura paulista: teatro e TV em São Paulo, 1940-1950. São Paulo, Códex.

Mello e Souza, Gilda de. (1980), “Teatro ao sul”. In: Exercícios de leitura. São Paulo, Duas Cidades.

Montenegro, Fernanda. (1998), Viagem ao outro: sobre a arte do ator. Rio de Janeiro, Fundacen.

Napolitano, Marcos. (2001), “A arte engajada e seus públicos, 1955-1968”. Estudos Históricos, 28, jun.

Oliven, Ruben. (2001), "Cultura e modernidade no Brasil”. São Paulo em Perspectiva, 15 (2), abr.-jun.

Pontes, Heloisa. (2004), “Ciudades e intelectuales: los 'neoyorquinos' de Partisan Review y los 'paulistas' de Clima entre 1930 y 1950”. Prismas, Revista de Historia Intelectual, Buenos Aires, ano 8 (8): 183-204.

- (2008), Intérpretes da metrópole: história social e relaçôes de gênero no teatro e no campo intelectual, 1940-1968. Campinas, tese de livre-docência, Departamento de Antropologia, Unicamp.

. (no prelo), "Campo intelectual, crítica literária e gênero (1920-1968)". In: Altamirano, Carlos (org.), Historia de los intelectuales en América Latina. Buenos Aires, Katz Editores.

Prado, Décio de Almeida. (1986), "A moratória". In: Andrade, Jorge. Marta, a árvore, o relógio. 2. ed. São Paulo, Perspectiva.

(1988), O teatro brasileiro moderno. São Paulo, Perspectiva.

Prado, Luis André do. (2002), Cacilda Becker: fúria santa. São Paulo, Geração Editorial.

Ratto, Gianni. (1996), A mochila do mascate. São Paulo, Hucitec.

Ridenti, Marcelo. (2000), Em busca do povo brasileiro: artistas da revolução, do CPC à era da TV. Rio de Janeiro, Record.

SCHORSKE, Carl. (1998), "Grace and the word: Austria's two cultures and their modern fate". In: . Thinking with history: explorations in the passage to modernism. Princeton University Press. . (1993), Viena fin-de-siècle: politica e cultura. São Paulo, Companhia das Letras. SCHWARZ, Roberto. (1978), "Cultura e política, 1964-68”. In: . O pai de familia e outros estudos. Rio de Janeiro, Paz e Terra. 
Sfatt, Dina \& Caballero, Mara. (1988), Dina Sfat: palmas pra que te quero. 2 ed. Rio de Janeiro, Nórdica.

\section{Resumo}

Teatro, gênero e sociedade no Brasil (1940-1968)

A apreensão das relações entre a cidade, a vida intelectual, a universidade e o teatro, sob o prisma da história social da cultura e das relações de gênero, pressupõe uma atenção especial às marcas da experiência social e à sua retradução em formas simbólicas específicas. Se em alguns contextos, a relação entre o teatro, a universidade e a cidade sinaliza caminhos divergentes, em outros ela aponta para trilhas convergentes, que expressam similitudes formais e sociais, como procurei mostrar no artigo, a partir da análise do que ocorreu nas décadas de 1940 e 1950 na cidade de São Paulo, onde se implantou um sistema cultural sem precedentes na história brasileira. Daí a escolha por justapor duas experiências distintas, o teatro e o trabalho intelectual, para ressaltar a urdidura sociológica que os alinhavou sincronicamente em uma mesma trama cultural.

Palavras-chave: São Paulo; Intelectuais; Atrizes; Jorge Andrade; Dramaturgia.

Texto recebido em $1 / 2 /$

201 e aprovado em $24 /$ $2 / 2010$

Heloisa Pontes é professora livre-docente do Departamento de Antropologia da Unicamp, pesquisadora do Pagu, Núcleo de Estudos de Gênero dessa mesma universidade, e pesquisadora do Cnpq). É autora, entre outros, de Destinosmistos (Companhia das Letras, prêmio Cnpq-Anpocs de melhor obra científica em ciências sociais editada no Brasil em 1998), de Intérpretes da metrópole (noprelo).E-mail: $<$ helo pontes@uol.com.br>.

\section{Abstract}

\section{Theater, gender and society (1940-1968)}

Grasping the relations between the city, intellectual life, the university and the theater through the prism of the social history of culture and gender relations requires close attention to the characteristics of social experience and its retranslation into specific symbolic forms. Whilst the relationship between theater, the university and the city signaled diverging paths in some contexts, in others those routes converged in formal and social similarities, as I hope to show in this paper by analyzing the situation in São Paulo during the 40s and 50s - a time that saw the implementation of a cultural system without precedent in Brazilian history. Hence the decision to juxtapose two distinct experiences, those of theater and intellectual output, in order to underscore the sociological warp that aligned them synchronically in the same cultural weft.

Keywords: São Paulo; Intellectuals; Acresses; Jorge Andrade; Dramaturgy. 